\title{
Ciência e tecnologia no Brasil Imperial Guilherme Schüch, Barão de Capanema (1824-1908) *1
}

\section{Science and technology in Imperial Brazil Guilherme Schüch, Baron of Capanema (1824-1908)}

\author{
SILVIA FERNANDA DE MENDONÇA FIGUEIRÔA \\ Professora-associada do Depto. de Geociências Aplicadas ao Ensino \\ Instituto de Geociências/UNICAMP \\ Livre-docente em História das Ciências (UNICAMP) - Pesquisadora 1-D / CNPq \\ R. João Pandiá Calógeras, 51 - Cidade Universitária - CEP: 13083-970 \\ (figueroa@ige.unicamp.br)
}

RESUMO O engenheiro e naturalista Guilherme Schüch de Capanema foi, sem dúvida, um expoente da elite Imperial. Circulou por importantes

\footnotetext{
Artigo recebido em 16/02/2005; Aprovado em 24/03/2005.

1 Este texto consolida, em versão escrita, as apresentações orais realizadas nos seguintes congressos, de que apenas os resumos publicados: FIGUEIRÔA, S. F. de M. Guilherme Schüch de Capanema and technical culture in 19th century Brazil. In: INT. CONG. HIST. SCIENCE, 21, 2001, México, DF. Abstracts... México, DF, 2001, p.415-16; FIGUEIRÔA, S. F. de M. Guilherme Schüch de Capanema, science and technology in 19th century Brazil: a biographical window. In: ANNUAL CONG. GEOL. SOC. AMER., 2001, Boston. Abstracts..., Boston, GSA, 2001. v.33, n.6, p.A59; FIGUEIRÔA, S. F. de M. Um construtor (quase) esquecido da ciência e tecnologia no Brasil: Guilherme Schüch de Capanema (1824-1908). In: XVII Encontro Regional de História (ANPUH-SP), Resumos..., v. único, Campinas-SP, 6 a 10 set/04, p.273; FIGUEIRÔA, S. F. de M. Ciências geológicas e mineração na obra técnico-científica de Guilherme Schüch de Capanema (18241908). In: XLII Congresso Brasileiro de Geologia (SBG), Resumos..., v. único (CD-ROM), Araxá-MG, 17 a 22 out/04. A pesquisa que o embasa contou com apoio financeiro da CAPES (Proc. BEX 2128/01-2) e do CNPq (Proc. 30.3275/02-2), instituições às quais a autora agradece. Cópia do inventário analítico dos fundos do Arquivo Histórico do Museu Histórico foi-me gentilmente cedida pela historiadora e funcionária do Museu, Rosangela de Almeida Costa Bandeira, e cópias de alguns documentos me foram emprestadas pela doutoranda Rachel Pinheiro (DGAE/IG/UNICAMP), a quem agradeço publicamente. Registro meu reconhecimento à diretora dos arquivos da Technische Universität zu Wien, Dra Juliane Mikoletzki, assim como ao

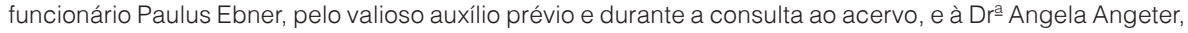


espaços institucionais científicos e técnicos, tendo atuado de forma bastante significativa para a implementação de uma cultura técnico-científica no Brasil e o conseqüente fortalecimento da engenharia e dos engenheiros. Entretanto, Capanema ainda permanece, assim como quase todos os cientistas do Segundo Império, um "desconhecido mal conhecido". O presente trabalho, contudo, não se propõe fazer sua extensa biografia, mas analisar e ressaltar aspectos de sua obra, relacionandoos a sua formação universitária e a sua prática enquanto engenheiro e naturalista.

Palavras-chave Guilherme de Capanema, Engenharia no Brasil, Ciência no Brasil

ABSTRACT Guilherme Schüch de Capanema was a prominent member of the Brazilian imperial elite. He belonged to several important institutional loci giving his valuable contribution to the implementation of a technical-scientific culture in Brazil, and therefore to the strengthening of both the field of engineering and the engineers. However, Capanema still remains an "unknown not well known", as do the majority of the scientists of the Second Empire. This paper analyzes and stresses aspects of his professional and academic life, related to his university education, and to his practice as engineer and naturalist.

Key words Guilherme de Capanema, engineering in Brazil, science in Brazil.

\section{Introdução}

Em trabalho anterior tive a oportunidade de me manifestar a respeito de Guilherme Schüch, barão de Capanema (1824-1908): "figura certamente interessante, Oscar Nerval de Gouvêa, assim como [Frederico Leopoldo Cesar] Burlamaqui e Capanema, está a merecer um estudo detalhado de sua vida e de sua obra" (Figueirôa, 1992). As pesquisas que empreendi desde então, bem como trabalhos de outros historiadores da ciência e da tecnologia no Brasil, só vieram confirmar a importância de Guilherme de Capanema no cenário brasileiro do século XIX. Entretanto, nenhum trabalho específico sobre ele foi produzido até o momento. $^{2}$

do Institut Österrreiches Biographisches Lexikon und biographische Dokumentation (Viena) pelas cópias de materiais dos arquivos. Também agradeço aos arquivistas Mme. Pasteur (CNAM-Paris) e M. Brunet (École Polytechnique de Paris) pela presteza e atenção durante a consulta, que em muito facilitaram meu trabalho

2 Recentemente, alguns trabalhos focalizaram com maior ou menor detalhe momentos precisos da vida científica de Capanema: SÁ, Magali R. O botânico e o mecenas: João Barbosa Rodrigues e a ciência no Brasil na 
O engenheiro e naturalista Guilherme (Wilhelm) Schüch, Barão de Capanema foi, sem dúvida, um expoente da elite imperial que circulou por importantes espaços institucionais científicos e técnicos, tendo atuado de forma bastante significativa para a implementação de uma cultura técnico-científica no Brasil e para o conseqüente fortalecimento da engenharia e dos engenheiros, assim como das ciências geológicas e naturais. Sua trajetória profissional, talvez até por circunstâncias da origem familiar - já que seu pai chegou ao Brasil como integrante da comitiva da Imperatriz Leopoldina de Habsburgo - , esteve inextricavelmente vinculada ao Segundo Império.

\section{2. $O$ cenário}

O século XIX já foi reconhecido por muitos autores, das mais diversas correntes historiográficas, como aquele do entusiasmo pelo progresso alicerçado na ciência e na tecnologia. Abandonando a matriz artesanal dos séculos precedentes, que possuía seus caminhos próprios e de certa forma independentes, as técnicas foram se aproximando cada vez mais das ciências, gerando o que hoje corrente e, sem grandes divergências, se chama tecnologia. Como um dos resultados desse processo de transição, longo e não-linear, pode-se apontar a substituição dos mestres e artesãos por cientistas e engenheiros, que foi acompanhada, simultaneamente, por mudanças no modelo de transmissão de conhecimentos e de formação profissional: dos mestres e aprendizes nas corporações de ofício e nas oficinas de manufaturas, passou-se à educação universitária, à organização profissional e a uma bibliografia especializada de caráter acadêmico. Foi sobretudo ao longo do século XVIII, e sobretudo no XIX, que se produziu o conjunto de condições que conferiram ao grupo sua identidade específica: sistema de formação, carreira definida, título profissional, status social.

Como categoria e profissão, os engenheiros vão de início atuar amplamente na esfera militar, na demarcação de fronteiras, na cartografia e na construção de fortificações, mas nas primeiras décadas do século XIX a participação nas obras civis é digna de nota, e crescerá rumo às atividades industriais. Esse vasto leque de atribuições teve como denominador comum os processos de produção de saberes e de objetos téc-

segunda metade do século XIX. Manguinhos - História, Ciências, Saúde, v.VIII, suplem., p.899-924, 2001; Moreira, Ildeu de C. e Silva, Mauro da C. Capanema: um professor de física cria a telegrafia elétrica no Brasil. Física na Escola, v.2, n.2, 2001, p.31; PINHEIRO, Rachel. As histórias da Comissão Científica de Exploração (1856) na correspondência de Guilherme Schüch de Capanema. Campinas: IG/UNICAMP, Dissert. de mestrado, 2002. 205p.; MARINHO, Pedro E. de M. M. A Engenharia Imperial. O Instituto Politécnico Brasileiro (1862-1880). Rio de Janeiro: Dissert. de mestrado, 2002. Também o prof. Paulo Pardal conduziu uma pesquisa histórica sobre a cidade de Barra de São João (RJ), onde Capanema teve uma bela casa, conforme pude constatar pelas fotos que ele gentilmente me enviou diretamente dessa cidade. 
nicos, e de organização e controle do trabalho coletivo em suas várias etapas (Grelon, 2001). Importância crucial — mas por vezes negligenciada - tiveram os professores das escolas profissionais, que desempenharam papéis plurais dada sua inserção particular, mediando demandas de mercado e de formação específica, políticas públicas educacionais, industriais, de apropriação do espaço e dos recursos naturais.

A engenharia desenvolveu-se, desde então, a pleno vapor, incorporando, descobrindo e desenvolvendo novos materiais, técnicas e equipamentos, alterando e, ou modernizando processos produtivos, transformando radicalmente as paisagens urbanas, agrícolas e "selvagens", ao mesmo tempo em que também se transformava sob esse impulso, desdobrando-se em diferentes especialidades. Na medida em que esses novos ramos se desenvolveram, seus representantes também foram sendo formados dentro da tradição do ensino superior, altamente especializado, com educação própria e atuação específica dentro da realidade social:

a criação dos cursos universitários de engenharia, assim como a fundação de associações profissionais e a publicação de periódicos especializados inserem-se nesse contexto de passagem da tecnologia para os domínios da ciência. Como fenômeno histórico, esse processo apresentou caráter universal, e estendeu-se a todas as sociedades em que as transformações provocadas pela Revolução Industrial tiveram impacto (Cury, 2001).

Os engenheiros se mostraram, a um só tempo, não apenas os iniciadores de numerosas mudanças técnicas, mas também os organizadores e administradores dos novos sistemas técnicos, garantindo sua continuidade e correta implementação (Grelon, 2001).

O Brasil acompanhou esse movimento, numa relação, como não poderia deixar de ser, permeada de contradições, posto que o desenvolvimento tecnológico se deu integralmente no apoio à implementação de uma economia agro-exportadora, que ao mesmo tempo em que foi estimulante também delimitou seu alcance, no limite de uma industrialização tardia. Desde a transferência da Corte em 1808, ampliaram-se os espaços institucionais para a formação de profissionais engenheiros, devido à consciência de alguns homens fortes do governo, como o ministro D. Rodrigo de Sousa Coutinho, quanto à significativa defasagem do Império português em relação à Revolução Industrial em curso. Primeiramente, foi criada a Academia Real Militar (1810), depois transformada em Escola Militar (1839), seguida da Escola Central (1855) — herdeira do ramo civil da engenharia, que então se separava definitivamente da engenharia militar no país - , e transformada em Escola Politécnica do RJ em 1874 (Figueirôa, 1995). Em 1875, surge também a Escola de Minas de Ouro Preto, destinada a fomentar a geração de profissionais 
para a área da mineração, mas que, rapidamente, teve que se adequar às demandas concretas e abrir outras modalidades de cursos (CarvaIho, 1978; Figueirôa, op. cit.), dentre outras escolas de engenharia que se seguiram.

As principais atividades, no Brasil, dos engenheiros no último quartel do século XIX eram a construção de edifícios, os estudos e projetos de portos e o projeto e construção de estradas de ferro (Vargas, 1994). Não obstante, os profissionais buscaram, no rastro do surgimento da Politécnica e do surto de modernização vivido pelo Brasil pós-1870, solidificar sua ação por meio de organizações associativas profissionais e técnico-científicas, ampliando espaços de atuação e conquistando novos, projetando a categoria em termos de importância social dado seu saber competente. Na transição para o século XX, no nível político, situase o apogeu do processo de consolidação do Estado oligárquico (Martins, 1976). No nível social, constituía-se uma sociedade predominantemente urbanizada e burguesa, e as classes médias e as elites acreditavam que, por fim, atingiam o que tanto almejavam, isto é, o 'nível de civilização' dos países avançados.

Esse momento também expressa, no campo técnico-científico, o desabrochar da cisão entre "ciência pura" e "ciência aplicada", inexistente até então. Socialmente, as bases dessa dicotomia assentavam-se na oposição entre bacharéis - e seu saber "ornamental" —, e engenheiros e militares - e seu saber "instrumental" - , pois os últimos transformavam o conhecimento científico em instrumento de ascensão social (Martins, op. cit.). Essa cisão se vinha gestando desde a introdução do Positivismo, em meados do XIX, e se alargará pelas décadas seguintes, em boa medida devido à crescente influência dos engenheiros e de seus modos de ver e pensar. Como aponta Cury (op. cit., p.12),

lançadas as bases do campo, portanto, determinadas as suas fronteiras, coube aos engenheiros brasileiros continuar a definir, de maneira cada vez mais clara e objetiva, a legitimidade de suas atribuições enquanto corpo destacado de profissionais especializados. Somente através dessa identidade determinada tornou-se-Ihes possível reivindicar o reconhecimento social e políticos para suas aspirações, e garantir a apropriação de seu capital cultural específico. Em certo sentido, uma das principais frentes de luta à qual se entregaram foi a da regulamentação profissional, que incluía a substituição dos tradicionais critérios "políticos" pelos novos critérios "técnicos" para a atribuição de funções na burocracia pública.

De forma complementar e esclarecedora do papel decisivo dos engenheiros em aspectos da vida nacional vale citar Turazzi (1989, p.16) quando destaca que, na virada para o século XX, as relações entre indústria e engenharia 
demarcam historicamente no Brasil a gênese das estratégias do capital para controlar o processo de trabalho industrial (...). Compreende-se que a organização do trabalho nas manufaturas e fábricas era particularmente condicionada pela necessidade de construção e afirmação do papel dirigente de engenheiros e industriais (...).

Nesse quadro, a pergunta que se coloca é: como Guilherme de Capanema, cuja vida transcorre entre a emergência da engenharia civil e os primórdios da industrialização brasileira, integra e colabora na construção desse contexto?

\section{O personagem}

\subsection{Formação}

Guilherme Schüch nasceu em Minas Gerais (em Timbopeba, nos arredores de Mariana-MG), filho do austríaco Roque (Rochus) Schüch, bibliotecário e conservador do Gabinete de História Natural da Imperatriz Leopoldina. Guilherme de Capanema ingressou no Imperial Instituto Politécnico de Viena no ano letivo de 1841-42 (com 17 anos, portanto) e prosseguiu seus estudos por 5 anos (ano letivo de 1845-46), ${ }^{3}$ como bolsista do Imperador Pedro II e sempre com a autorização de estudos da administração superior da instituição escolar, pois era aluno estrangeiro. Por quê a escolha dessa instituição? Evidentemente, as razões de origem familiar e a longa ligação de Rochus Schüch a serviço do Imperador austríaco devem haver estado em primeiro plano. Um exame mais detido dessa instituição e dos cursos freqüentados por Capanema pode, todavia, indicar-nos motivações adicionais.

O Imperial Instituto Politécnico de Viena foi fundado em 1815 por iniciativa do Imperador Francisco I, sob a direção do importante químico Johann Josef Prechtl (1778-1854), que Ihe imprimiu forte caráter aplicado e reforço na formação em química ao longo dos 35 anos em que dirigiu a instituição. Na sua conferência de abertura, Prechtl assim resumiu a missão do instituto recém-fundado: "o instituto politécnico se pretende um instituto técnico, um museu técnico e uma academia de ciências técnicas". ${ }^{4} \mathrm{O}$ ensino era livre - isto é, os alunos escolhiam as disciplinas que queriam cursar - e a idade mínima de ingresso era de 16 anos. ${ }^{5} \mathrm{~A}$ instituição possuía duas grandes linhas de treinamento: uma técnica e outra comercial e, como era regra geral nessa época para as escolas de formação técnica, não conferia diploma.

3 Technische Universität zu Wien - Universitätsarchivs. Prüfungs Katalog der Technische Abteilung der k. k. Polytechnische Institut im Studieren Jähre 1842, 1843, 1844, 1845 und 1846.

4 Cf.: http://www.tuwien.ac.at, acesso em 04/06/02.

5 Maiores informações sobre a história da instituição em: MIKOLETSKI, 1997. 
Capanema permaneceu o tempo máximo permitido de 5 anos e mesmo com a morte do pai enquanto lá estava, não regressou, e cursou todas as disciplinas disponíveis, tendo sido aprovado com boas notas: no $1^{\circ}$ ano, Matemáticas Elementares, Química Técnica Geral e Tecnologia (esta última, na verdade, um curso que apresentava a história da técnica e da tecnologia); no $2^{\circ}$ ano, Matemáticas Avançadas, Física, Geometria Descritiva, Desenho de Edificações e Técnica de Construções Geométricas; no 3ํano, Funcionamento de Máquinas, Técnicas Mecânicas, Geometria Prática, Geodésia e Topografia; no 4ํano, Química Aplicada, Arte de Minas, Ciência de Minas, Geometria Prática, Economia Mineral, Contabilidade Mineral e Desenho Arquitetônico; Construção de Estradas e Canais (hidrografia, pontes e canais), no 5e e último ano, Ciências Aplicadas às Pontes, Canais e Estradas, Desenho de Máquinas relacionadas à Hidrografia e Hidrologia, Economia Mineral e Contabilidade Mineral.

Talvez, neste conjunto de disciplinas em que se sobressai, de um lado, a formação em Mecânica e, de outro, em exploração e administração de minas, encontre-se uma chave para compreender a opção de formação, visando talvez administrar as minas da família ${ }^{6}$ e tornar-se empresário de mineração, além de toda a sua forte atuação como "engenheiro mecânico". Em 1846-47 Capanema estudou em na Academia de Minas de Freiberg ${ }^{7}$ para completar sua formação, o que só reforça a hipótese citada.

Não é preciso falar da Bergakademie Freiberg, sobejamente conhecida, mas talvez seja oportuno avaliar o que significou o Imperial Instituto Politécnico de Viena em sua época, pois são bastante raros os trabalhos sobre sua história. Citemos como testemunho um contemporâneo: o belga van den Corput, médico com vasto currículo, que visitou em missão oficial algumas escolas de ensino superior da Europa a fim de contribuir para pensar uma reforma do ensino técnico em seu país. Diz ele em 1866:

Dentre os numerosos materiais que recolhi de forma não sistemática percorrendo a maior parte da Europa, tomei, por base do trabalho que publico agora, a organização da Escola de Artes \& Ofícios de Viena, pela razão de que é,

6 Não sabemos exatamente quando, se antes mesmo ou após a morte da Imperatriz em 1826, Rochus Schüch envolveu-se em negócios de exploração de minas e metalurgia (ferro, ouro e também prata). Ao morrer em 4 de março de 1844 deixou em testamento uma doação para que o governo aplicasse numa escola de minas, quando esta viesse a ser criada (cf. Telles, op.cit.). O filho Guilherme sempre manteve negócios na área de minas e mineração (cf. documentos da Coleção Capanema, Arquivo do Museu Histórico Nacional), e possuía, no fim da vida, um considerável patrimônio em minas, como se percebe a partir de sua correspondência (Arquivo Histórico do Museu Imperial, Coleção Silva Costa. Cartas, cartões e bilhetes (109) a Miguel Arrojado Lisboa, tratando de diversos assuntos de propriedades de terras e jazidas. (1894 a 1904)).

7 Cf.: Festschrift zum hundertjährigen Jubiläum der Königl. Sächs. Bergakademie zu Freiberg. Freiberg, 1866, p.270. Capanema tem a matrícula no 1609 do ano de 1846. 
entre todas, a que achei a mais completa e, sob todos os aspectos, a que mais está em harmonia com as exigências da época. Instituições análogas existem em quase toda a Alemanha. Mas nenhuma pode rivalizar com as proporções grandiosas da Escola Politécnica de Viena,

e segue elogiando a estrutura dos cursos, a riqueza dos gabinetes de máquinas e das coleções de estudo. ${ }^{8}$ Assim, Capanema teve sua formação marcada por um curso técnico de certa forma exemplar, quer pelo aspecto das atividades práticas e da ênfase nos trabalhos de aplicação, quer pela atualidade em relação às demandas do século XIX.

\subsection{Ações como naturalista}

De retorno ao Brasil em 1847-48, ingressou por concurso como professor na Escola Militar e fez também as provas necessárias para obtenção do título de Doutor em Ciências Físicas e Matemáticas (Silva Telles, 1984). Embora a Escola fosse militar ele não o era, de modo que foi nomeado Capitão Honorário, pois nenhum docente poderia ficar de fora da hierarquia da congregação militar. Ensinava Física (era o responsável pelo Gabinete de instrumentos de Física) (Leonardos, 1963, p.162.), Matemática e Mineralogia e escreveu um pequeno Manual de Mineralogia - As apostillas de mineralogia do Dr. Capanema, publicado em 1858. Permaneceu como professor até meados da década de 1870, continuando assim na Escola Central que se desdobrou institucionalmente a partir da Escola Militar.

Desde seu regresso da Áustria e da Saxônia em fins da década de 1840, ainda muito jovem (contava cerca de 25 anos) começou a freqüentar o Instituto Histórico e Geográfico Brasileiro e se tornou um dos membros mais ativos. Ao longo de sua vida, em virtude de suas variadas atividades a serviço do governo, recebeu diversas condecorações, como a comenda das Ordens da Rosa e de Cristo, o título de Major Honorário do Exército e Conselheiro do Imperador (com quem se orgulhava de ter amizade pessoal), dentre outras (Blake, 1883-1902). De 1849 a 1876, quando se exonerou da instituição, foi adjunto da Seção de Geologia e Mineralogia do Museu Nacional. Em 1850, seus estudos identificaram, pela primeira vez no Brasil, a presença de cádmio em amostras provenientes do Ceará e pertencentes às coleções do Museu Nacional (Lopes, 1997). Pertenceu e ajudou a fundar a Sociedade Velosiana, chefiou a Seção de Geologia da Comissão Científica de Exploração das Províncias do Norte (também conhecida como Comissão do Ceará ou Comissão das Borboletas), e foi diretor da Repartição Geral dos Telégrafos desde meados da década de 1850 até o advento do regime republicano em 1889.

8 VAN DEN CORPUT, 1866. 
Manteve também ao longo da vida um vasto interesse em Botânica desde sua estadia acadêmica na Europa: figura entre os colaboradores da Flora Brasiliensis de Carl-Philip von Martius, apoiou constantemente o botânico brasileiro João Barbosa Rodrigues (Sá, 2001) e possuiu jardim botânico particular em sua propriedade:

\begin{abstract}
O antigo bairro do Capanema que, na língua Tupi, significa mato ruim, a partir de 1992 passou a se chamar Jardim Botânico. A mudança de nome, decidida em plebiscito popular, é referência a uma das paisagens mais bonitas da cidade, o Jardim Botânico Francisca Maria Garfunkel Rischbieter. No entanto, as ligações de seu nome anterior e do atual nome com o bairro já são antigas. Ainda no século XIX, grande parte das terras da região pertencia ao Conselheiro Guilherme S. de Capanema, conhecido como o Barão de Capanema. Respeitado cientista e amante da natureza, o barão cultivava em sua chácara um belíssimo "jardim botânico" com pomares maravilhosos e plantas exóticas que levaram jornalistas na época da visita do imperador D. Pedro II a Curitiba (1880) a descrevê-lo como um "Jardim Botânico de primeira grandeza, digno de menção entre os melhores que possui o império. ${ }^{9}$
\end{abstract}

Vejamos a seguir, com um pouco mais de detalhe, a atuação de Capanema em alguns desses momentos.

\title{
3.3 Capanema no IHGB
}

O Instituto Histórico e Geográfico Brasileiro (IHGB) tem sido objeto de diversas investigações históricas, sob os mais variados pontos de vista (Guimarães, 1988; Domingues, 1989; Figueirôa, 1992; Schwarz, 1993; Zusman, 1994; Guimarães, 1994; Sandes, 1997). Essas análises são unânimes em apontar seu papel de destaque na construção de uma memória nacional, contribuindo assim, de forma decisiva, para o projeto imperial de formação de uma identidade nacional desde os primórdios de sua fundação em 1838. Dentre esses trabalhos, um deles destacou a contribuição do IHGB como espaço institucional para as ciências naturais, comparando-o, na ausência de instituição equivalente, a uma "Academia de Ciências" (Figueirôa, 1992), dada a presença marcante de assuntos e textos científicos nas reuniões, particularmente no Império, além do fato de diversos de seus membros, à parte exercerem várias funções, praticarem também atividades científicas de forma regular. Tal foi o perfil de nosso personagem, que participava ativamente das discussões, debatendo e lançando idéias, e publicava textos na Revista do Instituto (p. ex., o artigo Quais as tradições ou vestígios geológicos que nos levam à certeza de ter havido terremotos no Brasil? apresentado na sessão ordinária de 24 de novembro de 1854 e publicado no tomo 22 da Revista, em 1859).

9 Urbenauta Curitiba, acesso em 21/05/04. 
No plano institucional, esse grupo integrado por Capanema e do qual também faziam parte, entre outros, Manuel Ferreira Lagos, Manuel de Araújo Porto-Alegre (seu cunhado), Joaquim Manuel de Macedo, empenhou-se na realização de uma expedição científica inteiramente brasileira. A idéia fora lançada pela primeira vez em 1843 e repetida ao longo dos anos em diversos discursos e relatórios. ${ }^{10}$ Ao final de seu parecer criticando a obra sobre o Brasil escrita pelo viajante francês Conde de Castelnau, Manoel Ferreira Lagos mais uma vez insistiria nesse ponto, salientando especialmente as possibilidades de aplicação e de exploração do conhecimento adquirido. ${ }^{11}$

Em sua justificativa, Lagos apelava explicitamente aos engenheiros e naturalistas nacionais, dando pistas de um movimento maior, simultaneamente de reconhecimento social e de ampliação de espaços profissionais. Note-se que o Instituto Politécnico Brasileiro foi fundado nesse mesmo período, mais precisamente em 1862, no Rio de Janeiro. Nesse aspecto, é oportuno ainda mencionar que a partir de 1860 novas tecnologias estão emergindo, requisitando engenheiros para as mais diversas e novas funções que conheceriam novo patamar na II Revolução Industrial que se avizinhava (Grelon, op.cit., p.91).

Tal expedição começou a tomar forma a partir de 1856, quando o Imperador decidiu financiá-la, constituindo-se então a Comissão Científica de Exploração, concretizada na lei no 884 de 01/10/1856 (Braga, 1962, p.20). Dividia-se em 5 Sessões, autônomas quanto aos seus objetivos, mas encarregadas de colaborarem entre si: Seção Botânica, chefiada por Francisco Freire Alemão; Geológica e Mineralógica, por Guilherme Schüch de Capanema; Zoológica, por Manoel Ferreira Lagos; Astronômica e Geográfica, por Giacomo Raja Gabaglia; e Etnográfica, pelo conhecido poeta Antônio Gonçalves Dias. Além do papel ideológico de valorização dos aspectos científicos brasileiros, a proposta de trabalho da Comissão possuía também cunho marcadamente aplicado e tocava, assim, em pontos-chave que foram fundamentais à sua viabilização: possibilidade de descoberta de algum recurso natural "que em breve se tornasse dos mais lucrativos", ${ }^{12}$ fornecimento de subsídios à ação governamental (vias de comunicação, catequese indígena, exploração mineral, etc.), e cunho nacionalista da empreitada.

De 1859 a 1861 a Comissão percorreu sobretudo a Província do Ceará, além de partes do Maranhão e da região amazônica. Diretamente vinculado à Comissão, Capanema escreveu as instruções de viagens relativas a sua seção, o relatório da expedição e um artigo intitulado As

10 Rev. IHGB, tomo 22, p.135-159, 1859.

11 Rev. IHGB, tomo 19 (supl.), 1856, p.12.

12 cf. LAGOS, nota 10. 
secas do Ceará. Nas instruções, suas preocupações voltam-se para os critérios de identificação e classificação mineral — bastante atualizados se comparados com o que constituía a prática da Mineralogia à época, ${ }^{13}$ e uma área 'forte' da tradição mineira dos países germânicos onde obteve sua formação - além da descoberta e avaliação da viabilidade de exploração econômica de jazidas de metais. Mais tarde, em 1887, suas preocupações com as secas apareceriam novamente, quando tomou parte de um debate público, promovido pelo Instituto Politécnico, acerca de possíveis soluções técnicas para a seca do Nordeste.

A história detalhada da Comissão é longa e, embora mereça ser conhecida, não cabe aqui detalhá-la. ${ }^{14}$ Importa reter, para o que discuto nesse texto, que na Comissão casavam-se, de forma inextricável, ciência e técnica, investigação e aplicação.

\subsection{Capanema e associações científicas}

Outro envolvimento importante de Guilherme de Capanema foi com a criação das associações Palestra Scientifica e Sociedade Velosiana, já apontadas em outros estudos como uma iniciativa da própria comunidade científica de naturalistas brasileiros de criarem um espaço institucional mais especializado, separando-se — mas sem rompimento, pelo contrário —, do IHGB e de outras associações (Figueirôa, 1995. Lopes, 1997). Os seis signatários dos estatutos da Sociedade Velosiana - como a agremiação se chamou - , e ainda boa parte de seus sócios pertenciam aos quadros do IHGB, da Sociedade Auxiliadora da Indústria Nacional, do Museu Nacional e, ou da Escola Militar. Os proponentes compunhamse de Francisco Freire Alemão, Luis Riedel, Emilio Joaquim da Silva Maia, Guilherme Schüch de Capanema, Frederico Leopoldo Cezar Burlamaqui e Cândido de Azeredo Coutinho.

Se acompanharmos as atividades da Sociedade, veremos que os objetivos se traduziram em ações práticas. Embora com dificuldades na publicação dos trabalhos de seus membros, ${ }^{15}$ um exame dos títulos dos textos discutidos nas sessões e publicados mostra uma gama de temas práticos relacionados à realidade local:

pela seção de mineralogia tivemos a análise de um Sulfureto de Zinco contendo 'Cádmio', o qual nos fora remetido da província do Ceará pelo sr. J. J. de Saldanha Marinho; o mineral de que se trata não pode deixar de merecer interesse, porque parece ser esta a primeira vez que se encontra Cád-

13 Veja-se LOPES (1997, p.130) e OLDROYD (1996).

14 Para maiores informações e análises, ver BRAGA, op.cit., e a dissertação de mestrado de PINHEIRO, op.cit., nota 1.

15 No relatório de 1853 (Bibliotheca Guanabarense, 1854, p.119), Freire Allemão, então Secretário, queixava-se: "não concebo a existência duradoura de uma associação científica da natureza desta nossa sem a publicação de seus trabalhos. (...) Infelizmente é este objeto um dos grandes embaraços que esta Sociedade tem encontrado em sua marcha". 
mio no Brasil; em Zinco é o mineral muito rico e vale a pena de ser explorado; foi analisado pelo Dr. Capanema; (...) foi também apresentado pelo mesmo Dr. Capanema um itinerário de viagem pelo Tocantins do Sr. Manoel Lourenço de Sousa, da Província do Pará, pela seção de botânica apresentou o Sr. Freire Allemão os seus trabalhos a respeito de diversas plantas novas (...). O mesmo Sr. Dr. Freire Allemão deu a descrição de uma nova espécie de Machærium, que é um angelim, trabalho apreciável que não pode deixar de ser considerado como a ponta de um fio precioso que nos facilita a saída do grande labirinto que apresenta a determinação de nossas madeiras de lei; ${ }^{16}$ etc.

Essa comunidade buscava criar uma problemática científica própria, elegendo como objeto de investigação o Brasil. Como já apontado em outros trabalhos, foram iniciativas da elite intelectual brasileira da época dentro de seu projeto de construção do nacional no campo científico. ${ }^{17}$ Esse esforço pode ser ainda ilustrado, além da Comissão do Ceará e da Sociedade Vellosiana, pela Exposição Nacional de 1861, proposta e organizada por membros da SAIN e do Instituto Agrícola (sobretudo Burlamaqui), na qual "pela 1av vez no país ... uma nação inteira pode assistir ao inventário de sua riqueza" (Moreira, 1866. p.19). Ou pelos compêndios de ciências naturais, escritos por Silva Maia, adotados no Imperial Colégio de Pedro II, cuja principal característica era a ênfase dedicada à flora e à fauna brasileiras (Lorenz,1986, p.429).

\subsection{0 professor e engenheiro}

A atividade profissional de Capanema na Seção de Mineralogia do Museu Nacional, de 1849 a 1876, tinha seu complemento na Escola Militar, depois Escola Central, onde lecionou Mineralogia nos currículos de engenharia. Afora haver incentivado o ensino prático mediante o estímulo à aquisição e algumas doações de amostras, Capanema uniu-se aos esforços pela melhoria do acervo bibliográfico nos primeiros anos da Escola Central (Figueirôa, 1996). Ao mesmo tempo em que se faziam aquisições para atualização das coleções, os próprios professores trataram de elaborar seus compêndios: Burlamaqui escreveu um sobre Metalurgia e Montanística (o equivalente da atual engenharia de minas) ${ }^{18} \mathrm{e}$ Capanema compôs um guia de Mineralogia — as já mencionadas Apostillas de Mineralogia do Dr. Capanema ${ }^{19}$ —, adotado em suas aulas e mesmo posteriormente à sua saída para trabalhar na Repartição Geral dos Telégrafos. Essas ações ecoavam um movimento em curso na Esco-

\footnotetext{
16 Ibidem, p.3.

17 FIGUEIRÔA, 1995; KURY, 1999. Figueirôa denomina esse período como o de "construção de uma problemática científica nacional" e Kury como o de "nacionalização da ciência no Brasil".

18 cf. MOREIRA, op. cit.

19 CAPANEMA, G. S. de. Apostillas de mineralogia. s. I., s. ed., 1858. $91 \mathrm{p}$
} 
la Central, que foi bem sucedido em diminuir a abordagem essencialmente matemática e teórica aí adotada (Telles, 1984).

Foi nessas escolas profissionais que Capanema realizou suas primeiras e bastante vitoriosas experiências tecnológicas (Telles, op.cit). Em janeiro de 1851, 2 meses antes do governo assinar um contrato para iluminação a gás das ruas da cidade do Rio de Janeiro, Capanema produziu iluminação utilizando gás de mamona no Laboratório de Física da Escola Militar. E mais tarde, no mesmo ano, em cooperação com o coronel Polydoro Quintanilha Brandão, construiu um telégrafo elétrico com aparelhos disponíveis nos laboratórios da Escola Militar (aparelhos da prestigiosa firma francesa Bréguet) e enviou uma mensagem de uma sala a outra. O Ministro da Justiça, que demandava melhorias urgentes na comunicação interna do Império, sobretudo para controlar o tráfico ilegal de escravos após a Lei Eusébio de Queiroz, encarregou Capanema de construir uma linha telegráfica, finalmente inaugurada em 11 de maio de 1852, medindo $4,3 \mathrm{~km}$, contando $3 \mathrm{~km}$ de linhas subterrâneas. Na sua construção foram empregados escravos e presos da Casa de Detenção.

Após a primeira linha, o telégrafo começou a se estender pelo país, inicialmente em torno da Capital (atingiu Petrópolis em 1858) e depois para o Sul, atendendo às necessidades militares da Guerra do Paraguai. Uma estação de manutenção e uma pequena fábrica para construir equipamentos foram criadas por Capanema, em 1865, no Rio. Depois deste período, as linhas telegráficas cresceram rapidamente em direção ao norte e ao interior, numa epopéia que duraria até o primeiro quartel do século XX, particularmente com os trabalhos de Rondon e sua equipe. A ligação telegráfica entre as várias cidades da costa brasileira com a Europa foi realizada, em 1873 e 1874, por meio de cabos submarinos de companhias inglesas.

Como nos informam Moreira e Silva, ${ }^{20}$ o físico inglês William Thomson (posteriormente agraciado com o título de Lord Kelvin) e seu colega Fleeming Jenkin eram os engenheiros especialistas na colocação de cabos que supervisionaram as obras entre Recife e Belém:

uma interessante controvérsia técnica, política e econômica, envolvendo William Thomson e Fleeming Jenkin com Capanema, ocorreu em 1873. A Western and Brazilian Telegraph Company havia solicitado ao governo a dispensa de construção da ligação do cabo submarino para São Luís, na linha Recife-Belém. Capanema recusa a proposta britânica. Na disputa que se seguiu, Thomson, Jenkin, e outros engenheiros da companhia inglesa, por um lado, e Capanema e outros engenheiros brasileiros, pelo outro, produziram relatórios em oposição, uns contra e outros a favor de tal ligação. O embate estendeu-se de

20 MOREIRA, I. de C. e SILVA, M. C., op. cit. nota 1, p.31. 
1873 a 1876, quando uma expedição da marinha brasileira foi enviada ao local para fazer medidas e concluiu pela possibilidade técnica de se construir a linha até São Luís, o que a companhia inglesa teve de realizar.

Esses autores nos informam, ainda, da invenção feita por Capanema de um novo isolador (patenteado sob o número 4.171, em 1873, no Reino Unido) para as linhas telegráficas terrestres, pois devido às condições climáticas tropicais e ao intenso intemperismo em virtude das temperaturas elevadas e do alto teor de umidade, a conservação dos isoladores constituía um problema grave — problema, aliás, que ocupou as mentes de diversos técnicos e engenheiros de vários países durante longo tempo (Volatron, 2002). Isto levou Capanema a inventar um novo tipo, que não empregava peças metálicas.

Capanema foi inventor e empresário em diversos outros ramos. Por exemplo, inventou e produziu o Formicida Capanema, comercializado até o início do século XX. Na Coleção Capanema, depositada no Arquivo do Museu Histórico Nacional, encontram-se dezenas de cartas de usuários do produto que reconhecem a qualidade e agradecem-no pelo envio do produto. ${ }^{21}$ Foi também proprietário de uma fábrica de papel chamada Fábrica Orianda, situada em Petrópolis (RJ), tecnicamente original em comparação com outras manufaturas papeleiras, pois empregava, em seu processo produtivo, energia hidráulica obtida a partir de quedas d'água naturais. ${ }^{22}$ A propósito, é oportuno citar menção que aparece no álbum que a Companhia Fábrica de Papel de Petrópolis preparou para marcar presença na Feira Internacional de Amostras do Rio de Janeiro, realizada em 1933:

Petrópolis é a cidade pioneira e o berço da indústria do papel no Brasil. Data de mais de 70 anos a instalação do primeiro estabelecimento fabril, na cidade serrana. (...), empregando um processo rudimentar e oneroso, essa notável iniciativa, que já se reveste da significação de acontecimento histórico, foi devida ao eminente brasileiro Dr. Guilherme Capanema (Barão de Capanema) o qual tão úteis e relevantes serviços prestou ao país. ${ }^{23}$

O envolvimento de Capanema com os negócios de mineração permaneceu forte até o final de sua vida, como atesta sua vasta correspondência ${ }^{24}$ com Miguel Arrojado Ribeiro Lisboa, engenheiro formado pela

21 Arquivo do Museu Histórico Nacional, Coleção Capanema, Sub-série correspondência passiva (GScrp).

22 Cf. TELLES, op.cit..; e também: Arquivo Histórico do Museu Imperial. I-DIF-14.10.1857-Cap.c 1-2. Cartas (2) de Guilherme Schüch de Capanema a Augusto Delamare pedindo que enviasse notícias diariamente dos trabalhos efetuados na fábrica de papel e indagando sobre fornecimento e pagamento de papel na Paraíba, bem como sobre formigas. 14/10 e 19/10/1857.

23 LOPES, Raul. Era uma vez uma indústria de papel. Jornal de Petrópolis: 25/05 a 31/05/2002, Ano 5, n. 286.

24 Arquivo Histórico do Museu Imperial. I-DAS-1894/1904-Cap.c 1-109. Cartas, cartões e bilhetes (109) a Miguel Arrojado Ribeiro Lisboa, tratando de diversos assuntos relativos a minas e depósitos minerais de que era proprietário; autorizando-o, inclusive, a efetuar estudos da riqueza mineral da fazenda de Timbopeba, de sua propriedade. 
Escola de Minas de Ouro Preto e futuro técnico do Serviço Geológico e Mineralógico do Brasil.

Por privar da amizade pessoal de Pedro II e ser homem de sua confiança - foi preceptor de Mineralogia das princesas e, mais de uma vez, o Imperador solicitou sua autorização para apresentar como suas idéias formuladas por Capanema ${ }^{25}$ - Guilherme Schüch foi nomeado para comissões importantes, em que aspectos técnicos não se dissociavam de questões políticas. Tal foi o caso da Comissão Internacional do Metro, estabelecida em Paris em 1870, sob a presidência do General Arthur Morin, diretor do Conservatoire des Arts et Métiers de Paris. Desde finais do século XVIII, quando instituiu oficialmente o sistema métrico, a França não poupou esforços para que essas novas unidades de medida se tornassem o padrão das trocas comerciais no mundo todo. Porém, somente em meados do século XIX, após a realização das primeiras Exposições Universais e às portas da chamada II Revolução Industrial, condições mais propícias se apresentaram: "mas foi sobretudo na época da Exposição de 1867 que o movimento de opinião do mundo sábio e industrial se manifestou com mais intensidade" (Morin, 1873 (?), p.49).

O Brasil está entre os primeiros países a adotar oficialmente o sistema métrico decimal, pela lei imperial no 1.157 de 26 de junho de 1862 (Campos, 1952, p.11.), e o material-padrão foi feito na França e verificado pela comissão disso encarregada no Conservatoire des Arts et Métiers. ${ }^{26}$ A primeira tentativa de implantação no Brasil, entretanto, data de 1830, quando Cândido Batista de Oliveira (1801-1865), deputado à época, propôs a adoção do sistema métrico decimal francês em todo o Império, o que foi rejeitado. Batista de Oliveira, que estudara em Paris na École Polytechnique ${ }^{27}$ e na Ecole des Mines, ${ }^{28}$ representante diplomático do Brasil em Turim, São Petersburgo e Viena, membro do IHGB, professor da Escola Militar e depois da Escola Central, era colega muito próximo de Capanema (juntos fundaram a sociedade Palestra Scientífica) e lutou a vida toda pela implantação do novo sistema no Brasil. ${ }^{29}$

Mais de duas dezenas de países foram convidados a integrar em 1870 a Comissão Internacional do Metro, que deveria definir o novo padrão a servir de protótipo para os demais que se reproduziriam. A repre-

25 Arquivo Histórico do Museu Imperial. I-DIF-1862/1864-PII.B.c 1-8. Cartas e memorandos (8) de Pedro II, Imperador do Brasil, a Guilherme Schüch de Capanema: referindo-se à sessão da Diretoria do Instituto [Fluminense] de Agricultura; sobre as aulas de mineralogia às princesas; sobre a criação de uma fazendaescola, por intermédio do Instituto Agrícola; indagando se poderia utilizar as idéias de Çapanema sem revelar sua origem. 11/07/1862; 22/03 e 17/05/1863; 1/2 e 08/05/1864.

26 Archives du Conservatoire National des Arts et Métiers, Dépôt du Cadran Solaire, 5AA/5 et 6 - Registres des minutes des lettres expédiées (1857-1860 et 1860-1864).

27 Archives de l'École polytechnique - Titre VI (Personnel - élèves), Section 2 (élèves), Paragraphe b (auditeurs externes/élèves étrangers), Article 2 (Dossiers Particuliers), Carton 1 (1795-1845).

28 Association Amicale des Élèves de l'E.N.S.M.P. Annuaire. № 1 (1864).

29 Para mais detalhes do envolvimento de Cândido Batista de Oliveira, consultar: Moreira e Massarani, 1997. 
sentação brasileira, por intermédio de Capanema, se fez presente a partir de 1872. Seria natural esperar que Batista de Oliveira fosse o representante, mas sua morte em 1865 deve ter obrigado o governo a encontrar um substituto. Capanema encarregou-se da redação de uma "Circular de remessa" que acompanhava os padrões enviados às Províncias do Império já em 1872, com explicações sobre as medidas e suas equivalências, bem como com recomendações para conservação dos padrões. ${ }^{30}$

A inventividade e criatividade de Capanema também foram empregadas durante o mais importante conflito bélico do Império: a Guerra do Paraguai. O governo brasileiro enviou-o a Ipanema em 1863 para avaliar as condições da fábrica, prevendo a possibilidade de necessitar de armas e munições. Logo ao chegar, Capanema, em sua vistoria, construiu um pilar de alvenaria - com um relógio de sol na parte superior e os números das coordenadas geográficas nas laterais - no local em que passa o Trópico de Capricórnio. Durante o período da guerra (1864-70), foram produzidas no local munições e armas brancas usadas pelo exército brasileiro e por seus aliados. ${ }^{31}$

Como nos informa Castro (2003, p.1) "na década de 1850 começou um profundo processo de modernização e aperfeiçoamento do Exército, visando torná-lo uma ferramenta apropriada para execução das políticas e ações diplomáticas no exterior, em especial no Prata". Medidas de renovação técnico-administrativa foram tomadas, sendo "um dos mais importantes eventos a criação de um novo Laboratório Pirotécnico, no Campinho, destinado à fabricação de foguetes de desenho moderno". Nesse laboratório, diversos profissionais militares ou não, foram encarregados de pesquisas com armas e instrumentos do arsenal visando fazer "engenharia reversa", como foi o caso de Capanema, que fabricou cartuchos da espingardas Dreyse, um segredo do exército da Prússia (Castro, op. cit., p.3).

\section{Considerações finais}

Recuperar e reconstruir historicamente as trajetórias de vida de profissionais ainda hoje pouco lembrados, como Capanema, que exerceram diferentes papéis profissionais, permitiria esclarecer muitos pontos dos processos de institucionalização das ciências e da tecnologia no Brasil, basilares para a formulação de políticas de estímulo e investimento em C\&T. Tais pontos seriam, por exemplo: rever opções teóricas em

30 Circular de remessa dos padrões de pesos e medidas, assinada por Guilherme S. de Capanema em 10/05/ 1872. Rio de Janeiro, Typ. do Apostolo, 1872. In: Campos, 1952.

31 Agrella, Regina. O renascer de Ipanema. Website "Vida e Arte", acesso em 10/05/04. 
ciência e sua difusão local, compreender opções por determinados modelos institucionais, explicar laços de coesão e fraturas nas instituições científicas, identificar e analisar detalhes, características e nuances das relações entre ciência/tecnologia e Estado, etc., articulando, assim, num novo patamar qualitativo, nossos cientistas e nossas instituições do passado.

Não se trata de fazer a "biografia de grandes homens", ou justiça à memória de "pioneiros esquecidos". Mas de mostrar que é exatamente na interação inextricável, porém singular, entre indivíduo e contexto, idéias e "ambiente", que o conhecimento é produzido. Como insiste Shapin, "um indivíduo é um competente conservador da cultura a ele transmitida, [mas] sua vida e trabalho representam uma única trajetória entre a cultura e a circunstância" (Shapin, 1993, p.343).

Nossa investigação sobre a trajetória de Guilherme Schüch de Capanema ainda se encontra em andamento. ${ }^{32}$ No entanto, é possível afirmar que atuou de modo intenso nas mais diversas frentes que se apresentavam no transcorrer do $2^{\circ}$ Império - associações científicas e profissionais, comissões de levantamentos do território, pesquisa aplicada no Museu Nacional, formação de profissionais de engenharia -, constantemente orientado pela valorização do que se chamava à época 'elemento nacional' e marcado pela preocupação em criar uma cultura técnico-científica autóctone, ${ }^{33}$ encaixando-se de forma clara no perfil da "ilustração tardia" brasileira que se prolonga pelo Império (Dias, 1968). Diversamente do que nos foi transmitido, com raras exceções, pela historiografia pós-republicana, as ciências e a tecnologia estiveram, sim, presentes no Brasil desde a Colônia, assumindo as formas típicas e os limites de cada contexto. Não de forma abstrata, mas concretamente inseridas nas instituições e seus integrantes.

\section{REFERÊNCIAS BIBLIOGRÁFICAS}

BLAKE, A. V. A. S.. Diccionario bibliographico brazileiro. Rio de Janeiro: Typ. Nacional, 1883-1902. 7 vols. (reimpressão do Conselho Federal de Cultura, 1970).

BRAGA, R.. História da Comissão Científica de Exploração. Fortaleza: Imp. Univ. Ceará, 1962. 450p.

CAMPOS, Francisco de Barros. Padrões públicos de medir do Brasil. São Paulo: IPT, Boletim no 45, dez 1952. 46p.

32 Projeto "Ciência e tecnologia no Brasil através de um cientista do Império: Guilherme Schüch, barão de Capanema (1824-1908)"; ago/03 a fev/07, proc.CNPq ํㅡ 303275/02-2. O início, que permitiu levantamentos de fontes na França, Áustria e Alemanha, foi financiado por uma bolsa de pós-doutoramento outorgada pela CAPES de janeiro a dezembro de 2002 (Proc. BEX 2128/01-2).

33 Consultar a respeito: CAPANEMA, G. S. de; NOGUEIRA, B. C. de A.; RODRIGUES, J. B.. Ensaios de sciencia por diversos amadores. Rio de Janeiro, Brown \& Evaristo, 1876. v.I. 
CARVALHO, J. M. de. A escola de minas de Ouro Preto: o peso da glória. São Paulo: Ed. Nacional; (Rio de Janeiro): FINEP, 1978. 177p.

CASTRO, A. H. F. de. Foguetes no Brasil - do foguete CONGREVE ao VLS (2a. parte). 13 páginas, 2003. http://www.ufjf.edu.br/defesa, acesso em 08/04/04.

CURY, V. Mํ... Engenharia e desenvolvimento: questões da constituição do campo profissional no Brasil. Rio de Janeiro: UFRJ, 2001. 24p. (mimeo)

DIAS, M. O. da S.. Aspectos da ilustração no Brasil. Rev. IHGB, Rio de Janeiro, n.278, p. 105-70, jan-mar 1968.

DOMINGUES, H. B. A noção de civilização na visão dos construtores do Império (a revista do Instituto Histórico e Geográfico Brasileiro, 1838-1850/60). Niterói: ICHF/ CEG/UFF, 1989. (Dissertação de mestrado em História)

FIGUEIRÔA, S. F. de M.. "Ciência no torrão natal": a adaptação de modelos estrangeiros e a construção de uma problemática científica nacional (1840-1870). In: GOLDFARB, A. M. A.; MAIA, C. (orgs.). História da ciência: o mapa do conhecimento. São Paulo: Edusp, 1995. p.773-784.

FIGUEIRÔA, S. F. de M. Associativismo científico no Brasil: o Instituto Histórico e Geográfico Brasileiro como espaço institucional para as ciências naturais durante o século XIX. Interciência, v.17, n.3, p. 141-6, maio-jun 1992.

FIGUEIRÔA, S. F. de M. Engineering schools as institutional "loci" for geological sciences in Brazil during 19th century. Antilia: Madrid, v.1, n.1, jan/96. (revista eletrônica: http://www.ucm.es/OTROS/antilia)

GRELON, A. Emergence and growth of the engineering profession in Europe in the 19th and early 20th century. In: GOUJON, Ph.; DUBREIL, B. H. (eds.) Technology and ethics: a European quest for responsible engineering. Leuven: Peters, 2001. pp.7599.

GUIMARÃES, L. M. P. "Debaixo da imediata proteção de S. M. Imperial": o Instituto Histórico e Geográfico Brasileiro (1838-1889). São Paulo: FFLCH-USP, 1994. (tese de doutoramento em História Social)

GUIMARÃES, M. L. S. Nação e civilização nos trópicos: o Instituto Histórico e Geográfico Brasileiro e o projeto de uma história nacional. Estudos Históricos, Rio de Janeiro, n.1, 1988.

KURY, L. B. Ciência e Nação: Romantismo e História Natural na obra de Emílio Joaquim da Silva Maia. Manguinhos, Rio de Janeiro, v. VI, n.2, Jul-Out, 1999.

LEONARDOS, O. H.. O ensino da Geologia no Rio de Janeiro de 1811 a 1963. Engenharia, Mineração e Metalurgia, v.38, n.226, p.161-4, out 1963.

LOPES, Ma․ M. O Brasil Descobre a Pesquisa Científica: os museus e as ciências naturais no século XIX. São Paulo: Hucitec, 1997.

LORENZ, K. M. Os livros didáticos e o ensino de ciências na escola secundária brasileira no século XIX. Ciência e Cultura, v.38, n.3, p.426-35, mar 1986.

MARINHO, P. E. de M. M. A Engenharia Imperial. O Instituto Politécnico Brasileiro (18621880). Niterói: História/UFF, Dissert. de mestrado, 2002, 220p.

MARTINS, L. Pouvoir et développement économique: formation et évolution des structures politiques au Brésil. Paris: Ed. Anthropos, 1976.

MIKOLETZKI, J. Geschichtliche Entwicklung. Veröffentlichungen des Universitätsarchivs der technischen Universität Wien, Viena, Heft 3, pp. 5-67, 1997.

MOREIRA, I. de C.; MASSARANI, L. Cândido Batista de Oliveira e seu papel na implantação do sistema métrico-decimal no Brasil. Revista da SBHC, n.18, p.3-17, 1997.

MOREIRA, I. de C.; SILVA, M. da C.. Capanema: um professor de física cria a telegrafia elétrica no Brasil. Física na Escola, v.2, n.2, 2001. p.31.

MOREIRA, N. J.. Elogio historico pronunciado perante S. M. I. em sessão da Assembléia Geral da Sociedade Auxiliadora da Industria Nacional por occasião do acto solemne 
da inauguração do busto do Conselheiro Frederico Leopoldo Cezar Burlamaqui (Dr. em Mathematicas, Prof. Jubilado da Escola Central, Brigadeiro reformado, Director do Muzeu Nacional, Secretario Honorario Perpetuo e Presidente da Secção de Agricultura da mesma Sociedade, etc, etc, etc). Rio de Janeiro: Typ. Nac. de Cotrim \& Campos, 1866.

MORIN, A. Notice sur le système métrique. Annales du Conservatoire des Arts et Métiers, Paris, 1873 (?).

OLDROYD, D. Thinking about the earth: a history of ideas in geology. London: Athlone Press, 1996. 410p.

PINHEIRO, R. As histórias da Comissão Científica de Exploração (1856) na correspondência de Guilherme Schüch de Capanema. Campinas: IG/UNICAMP, Dissert. de mestrado, 2002. 205p.

SÁ, M. R. O botânico e o mecenas: João Barbosa Rodrigues e a ciência no Brasil na segunda metade do século XIX. Manguinhos - História, Ciências, Saúde, v.VIII, suplem., p.899-924, 2001.

SANDES, N. F. A invenção da nação entre a Monarquia e a República. São Paulo: FFLHCUSP, 1997. (tese de doutoramento em História Social)

SCHWARCZ, L. M. O espetáculo das raças: cientistas, instituições e a questão racial no Brasil (1870-1930). São Paulo: Cia. das Letras, 1993.

SHAPIN, S. Essay review: Personal development and intellectual biography: the case of Robert Boyle. British Journal Hist. Science, n.26, p.335-45, 1993.

TELLES, P. C. da S. História da engenharia no Brasil. Rio de Janeiro: Livros Téc. Cient. Ed., 1984. 510p.

TURAZZI, Mำ I. A euforia do progresso e a imposição da ordem: a engenharia, a indústria e a organização do trabalho na virada do século XIX ao XX. Rio de Janeiro: COPPE; São Paulo: Marco Zero, 1989.

van Den CORPUT. De l'organisation des écoles pratiques professionelles en Allemagne, en Suède et en Russie, et en particulier des écoles des Arts "Métiers de Vienne et de St. Petersbourg" (extrait des Annales du génie civil" de mars 1866 (5 $5^{\text {èe }}$ année)).

VARGAS, M. Introdução. In: VARGAS, M. (org.). História da técnica e da tecnologia no Brasil. São Paulo: Ed. Unesp/CEETEPS, 1994. 412p.

VOLATRON, J. P. Le verre et l'isolateur télégraphique. Paris, La revue du Musée des Arts et Métiers, n.36, p.53-61, set/2002.

ZUSMAN, P. B. O Instituto Histórico e Geográfico Brasileiro e a Sociedade Geográfica do Rio de Janeiro: continuidades e rupturas no marco do projeto imperial. In: SOUZA, Ma Adélia A. de. O novo mapa do mundo: natureza e sociedade de hoje - uma leitura geográfica. São Paulo: HUCITEC-ANPUR, 1994. 